\title{
VARIACIONES ICONOGRÁFICAS DE LA CRUZ EN EL CEMENTERIO GENERAL DE TACNA (1880 - 2000)
}

\author{
ICONOGRAPHIC VARIATIONS OF THE CROSS IN THE GENERAL CEMETERY OF TACNA (1880- 2000)
}

\author{
Elard Vladimir Chaiña Flores ${ }^{1}$
}

\begin{abstract}
RESUMEN
Esta investigación se realizó durante el periodo marzo 2014 - marzo 2015, sobre las variaciones iconográficas de la cruz, presente en las lápidas (1880- 2000) del Cementerio General de Tacna, siendo el objetivo principal la identificación, análisis e interpretación de la iconografía de la cruz. El estudio se centra en la comprensión iconográfica e iconológica del arte funerario. En tal sentido, se enmarca en la metodología de la investigación cualitativa y se concluye, que en el cementerio existen 11 variaciones iconográficas de la cruz que reflejan la realidad idealizada durante la Guerra del Pacífico y el Cautiverio de Tacna.
\end{abstract}

Palabras clave: Cruz, iconología, variaciones iconográficas.

\begin{abstract}
This research was carried out during the period between March 2014to March 2015, on the iconographic variations of the cross, present in the tombstones (1880-2000) of the General Cemetery of Tacna, the main objective of this work is the identification, analysis and interpretation of the iconography of the cross. The study focuses on the iconographic and iconological understanding of funerary art. In this sense, it is part of the methodology of qualitative research and it is concluded that, in the cited cemetery, there are 11 iconographic variations of the cross that reflect the idealized reality during the Pacific War and the Captivity of Tacna.
\end{abstract}

Keywords: Cross, iconology, iconographic variations.

\section{INTRODUCCIÓN}

Esta investigación analiza e interpreta las variaciones iconográficas de la cruz presente en las lápidas (1880 a 2010) del arte funerario del Cementerio General de Tacna, estudio que contribuirá al conocimiento de la iconografía usada en el ámbito urbano de ese tiempo y espacio, por lo que resulta importante estudiar las características y naturaleza de este legado histórico.

Se postuló el supuesto de que, las variaciones iconográficas de la cruz se desarrollaron de manera diversificada, en cuya base se diseña los objetivos de la investiga- ción: identificar y describir las variaciones iconográficas de la cruz en el Cementerio General de Tacna. Entre los factores importantes que motivaron la investigación, se tiene por un lado, la concepción iconográfica de los pobladores artistas de Tacna, plasmada en el arte funerario en un contexto de la Guerra del Pacífico, cautiverio y reincorporación al seno patrio, estudio que se prolonga hasta la primera década del siglo XXI y por otro, la existencia de obras de arte funerario de gran calidad, como lápidas y mausoleos de mármol predominantemente y otros materiales con el ícono de la cruz, lo que originó su investigación y estudio respectivo.

\footnotetext{
'Doctor en Ciencias Sociales y Magister en Arte. Facultad de Ingeniería Civil, Arquitectura y Geotecnia. Escuela Profesional de Artes, Universidad Nacional Jorge Basadre Grohmann. Tacna-Perú. E-mail: ee012126@hotmail.com

Presentado: 23/11/16 Aprobado: 10/08/17
} 
En este contexto se utilizó el método iconológico de Erwin Panofsky (1987), se realizó una caracterización pre icónico, análisis iconográfico e iconológico de la cruz y la moda-gusto estético desde una perspectiva hermenéutica.

\section{METODOLOGÍA}

La investigación centró su análisis, interpretación y comprensión iconológica de la cruz, arte funerario del Cementerio General de Tacna. En tal sentido, el objeto de estudio estuvo constituido por las variaciones iconográficas de la cruz de lápidas y mausoleos, cuya interpretación y comprensión iconológica: $1^{0}$ Identificación preiconográfica; $2^{\circ}$ Análisis iconográfico; $3^{\circ}$ Análisis icono- lógico (Panofsky, 1987). Dentro de la metodología de investigación cualitativa, que permitió reflexionar respecto a la visión del tiempo y espacio en que se manifestaron las obras objeto de estudio.

\section{EL CEMENTERIO GENERAL DE TACNA}

El estudio se realizó en el sector antiguo de nichos y mausoleos del actual Cementerio General de Tacna, en un área de estudio que comprende 6,574 lápidas (figura 1).

Históricamente, desde la Colonia se impuso la religión católica y con ello nuevas prácticas funerarias como los cementerios; en la ciudad de Tacna "el cementerio estaba ubicado en la parte posterior del

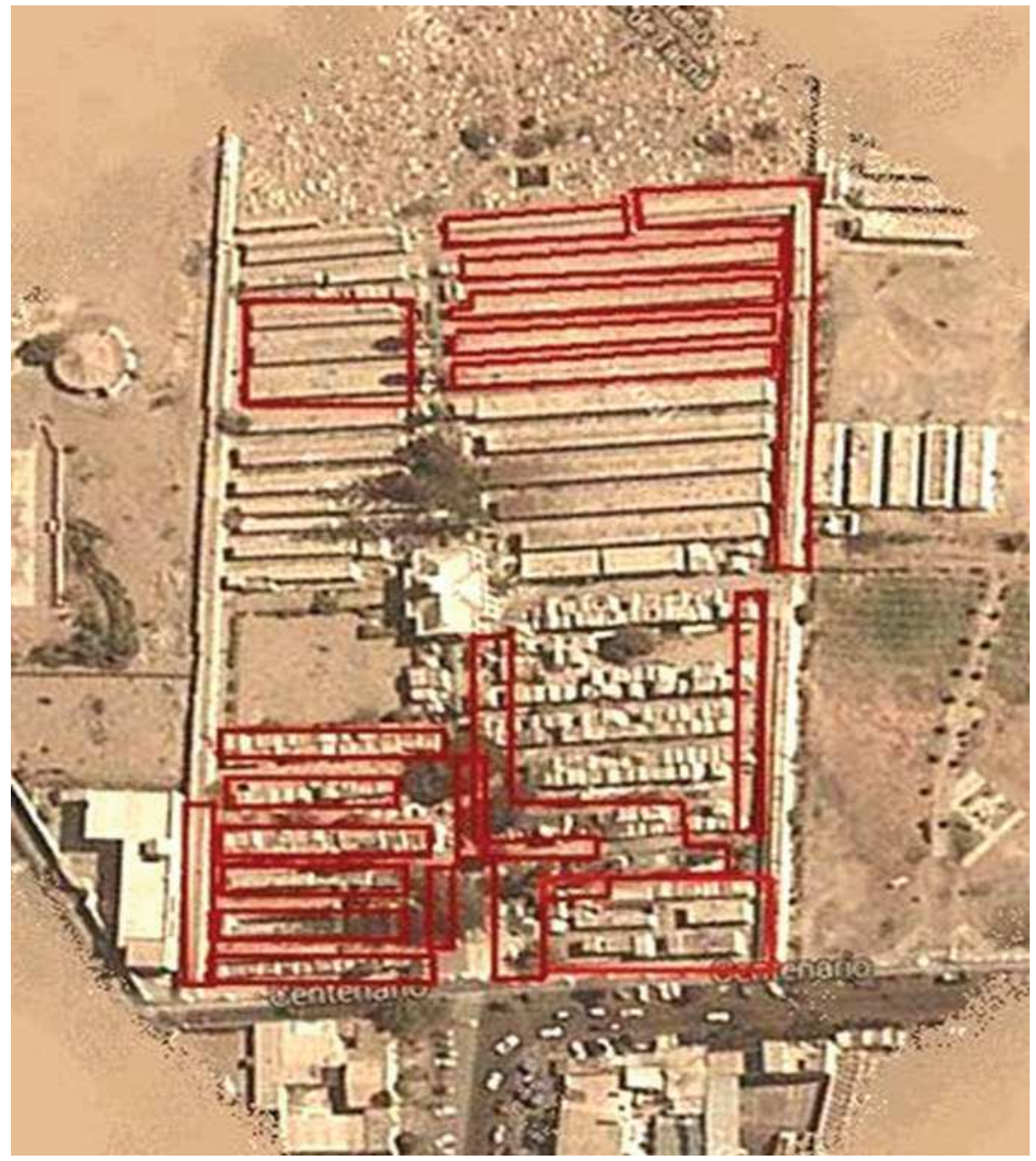

Figura 1. Área de estudio en el Cementerio General de Tacna Fuente: Chaiña (2014, p. 26) 
templo parroquial, actual catedral, en el sitio que ocupaba la cancha de tenis y después parque infantil, al derrumbarse el templo por la acción de unos de los tantos movimientos sísmicos que conmovieron a la ciudad de Tacna, se construyó un nuevo cementerio a inmediaciones de la población, hacia el noreste, donde existía un bosque de eucaliptos. Dicho bosque estaba en las proximidades del edificio de la estación del ferrocarril Tacna- Arica" (Zora, 1969, p. 185).

Es así, que "El cambio bistórico de la etapa republicana, trajo, no solo nueva organización política, sino cambios culturales que incluyeron a los patrones culturales funerarios" (Calvo, 2010, p. 12), amplia- mente discutidos en el Mercurio Peruano (Atanasio, 1964), la puesta en funcionamiento del Cementerio General de Lima "se producirá una sucesión de reformas urbanas en las áreas aledañas que conjugaban la utilidad racional con la ciencias y la estética" (Wuffarden, 2006, p. 131); en Tacna, el cementerio construido a instancias del presbítero Sors era exclusivamente para dar cristiana sepultura a católicos; fue "inaugurado el 17 de agosto de 1848; en sus comienzos fue más pequeño y se amplió posteriormente parte delantera" (Rueda, 1982, p. 114).

La capilla del Cementerio General de Tacna, según García (1981) fue "obra de Buenaventura Sors que data de 1859, es de aire decididamente schinkeliano

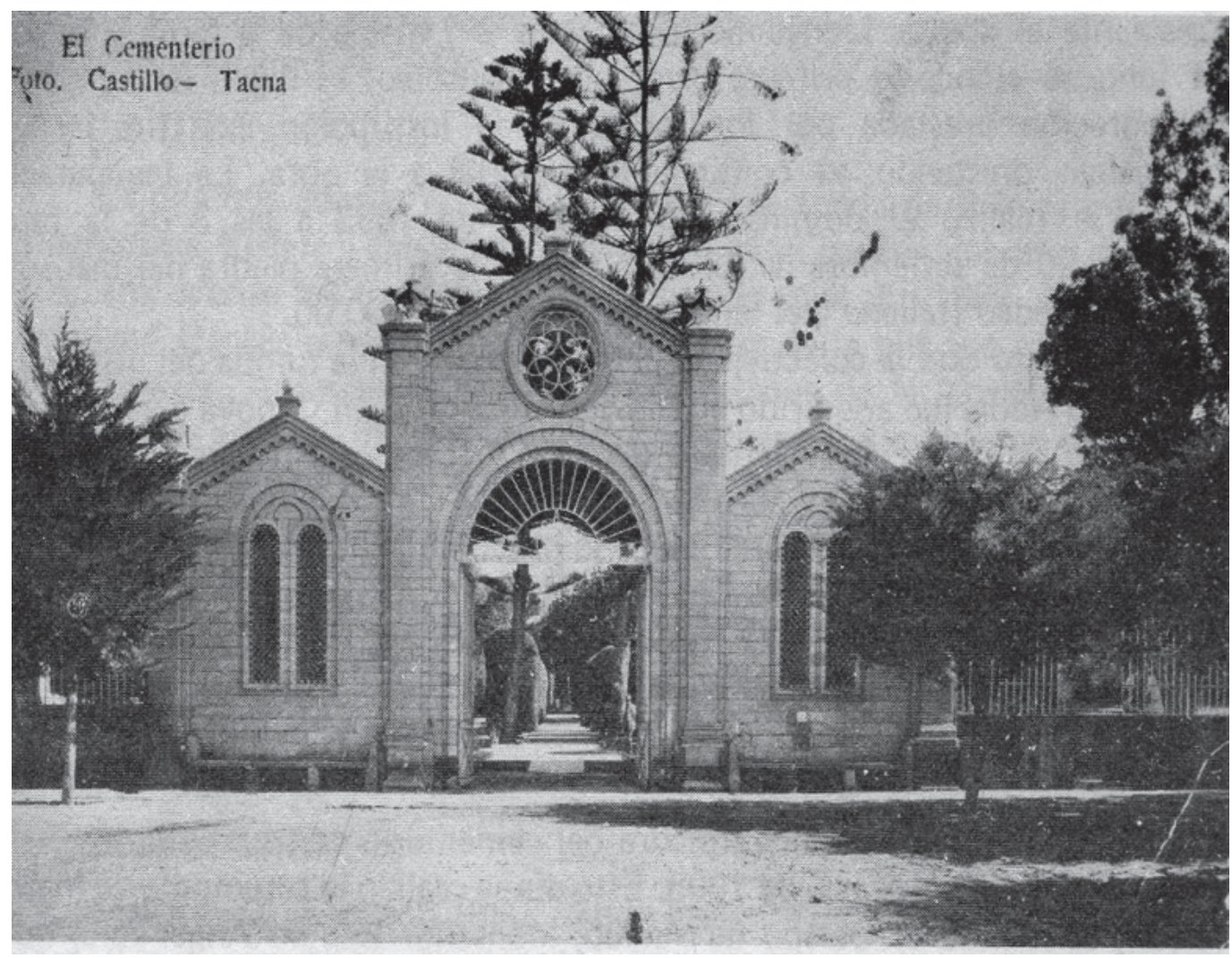

Figura 2. Fachada - Cementerio General de Tacna

Fuente: Tomado de Rueda Valverde, Nilo. 1982: 115. Historia del departamento de Tacna 
y posee singular interés histórico por corresponder el estilo de su arquitectura a lo que se conoce con el nombre de Renacimiento Griego ("Greek Revival"), modalidad que floreció predominantemente en el norte de Europa, Inglaterra y los Estados Unidos." (p. 117). Indudablemente neoclásico arquitectónico que adoptó la república por "la necesidad de un nuevo reordenamiento urbano y de control de los espacios públicos" (Rojas, 2017, p. 119), "asociado, [...] con elsaber ilustrado” (Mac Evoy, 2017, p.23).

Al parecer esta primera capilla a la que hace mención José García Bryce "fue destruida por el terremoto de 1868... Fue colocada la primera piedra del cementerio con sus columnas estilo griego el 28 de setiembre de 1905. [...]Los trabajos duraron 2 años, dirigidos por el arquitecto señor Eloy Martínez. Por el mes de setiembre de 1907 llegaba el altar para la capilla, construida en Génova en mármol blanco con alegorías y ornamentaciones talladas en la misma materia. La primera misa se dijo el 15 de abril de este añoy la inauguración oficial se efectuó el domingo 27 de octubre de 1907" (Rueda, 1982, p. 114-116).

Siendo su tipología de sepulcros, las tumbas contienen restos mortales bajo tierra, para su identificación se utiliza una lápida y/o cruz; Los nichos son construcciones del cementerio con cavidad en un muro que sirve para colocar un difunto, cubierto con una lápida; los mausoleos constituyen un monumento funerario levantado sobre la tumba de una persona, o nichos familiares. En la investigación se analizaron lápidas principalmente elaboradas en mármol y otros materiales símiles.

El ícono principal encontrado en las lápidas es la cruz, de cinco íconos recurrentes "Cristo, María, Cruz diagonal, Cruz verticaly Ángeles" (Chaiña, 2014, p. 26) de ahí la necesidad de conocer sus variaciones iconográficas. La cruz, desde 1532, fecha de la presencia hispana en el Perú, se impuso como un ícono con connotación católica, como menciona Burgos (S/f) "la cruz aparece en la Biblia como instrumento de la protección y salvación del pueblo de Dios [...] No solo describe los dos troncos de madera que formaron el instrumento de crucifixión, sino también todo lo que concierne a la muerte de Jesús" (p. 03). El hijo de Dios, murió en la cruz para redimir los pecados del mundo y luego resucitó, o como diría Morales (1986), para "la salvación de las almas pecadoras [...] en toda su imponente expresión de crucificado" (p. 10).

La "simpleza de la cruz presenta muchas ventajas: dos barras cruzadas pueden hacerse con cualquier material y pueden trazarse en el aire" (Millones y Tomoeda, 2010, p.19), estas dos líneas que se intersectan, donde "el tramo vertical más largo que el horizontal, es el símbolo de la cruz en que fue crucificado Jesucristo" (Dorling, 2008, p. 178), representa el sacrificio de Cristo para salvar la humanidad.

\section{RESULTADOS}

Se presenta en dos partes referidos al análisis iconográfico, primero identificación de variaciones icónicas de la cruz, encontradas en las lápidas del Cementerio General de Tacna y segundo referido a la cronología de las variaciones.

\section{Variaciones iconográficas de la cruz}

El análisis iconográfico se presenta en dos partes, primero se identificó las variaciones icónicas de la cruz encontradas en las lápidas y segundo referido a la cronología de las variaciones; el estudio se realizó en el sector antiguo de nichos y mausoleos (figura 1), dentro del "[...] arte funerario del Cementerio General de Tacna expresado en sus Lápidas, posee cinco íconos representativos: Cristo, María, Cruz diagonal, Cruz vertical y Ángeles" (Chaiña, 2014, p. 26), siendo el ícono de la cruz vertical poseedora de 11 variaciones iconográficas, sumando a esta la variación denominada cruz diagonal; 1054 lápidas poseen el ícono de la cruz distribuidas entre los años 1858 hasta el 2000, con 11 variaciones iconográficas (figura 4). 

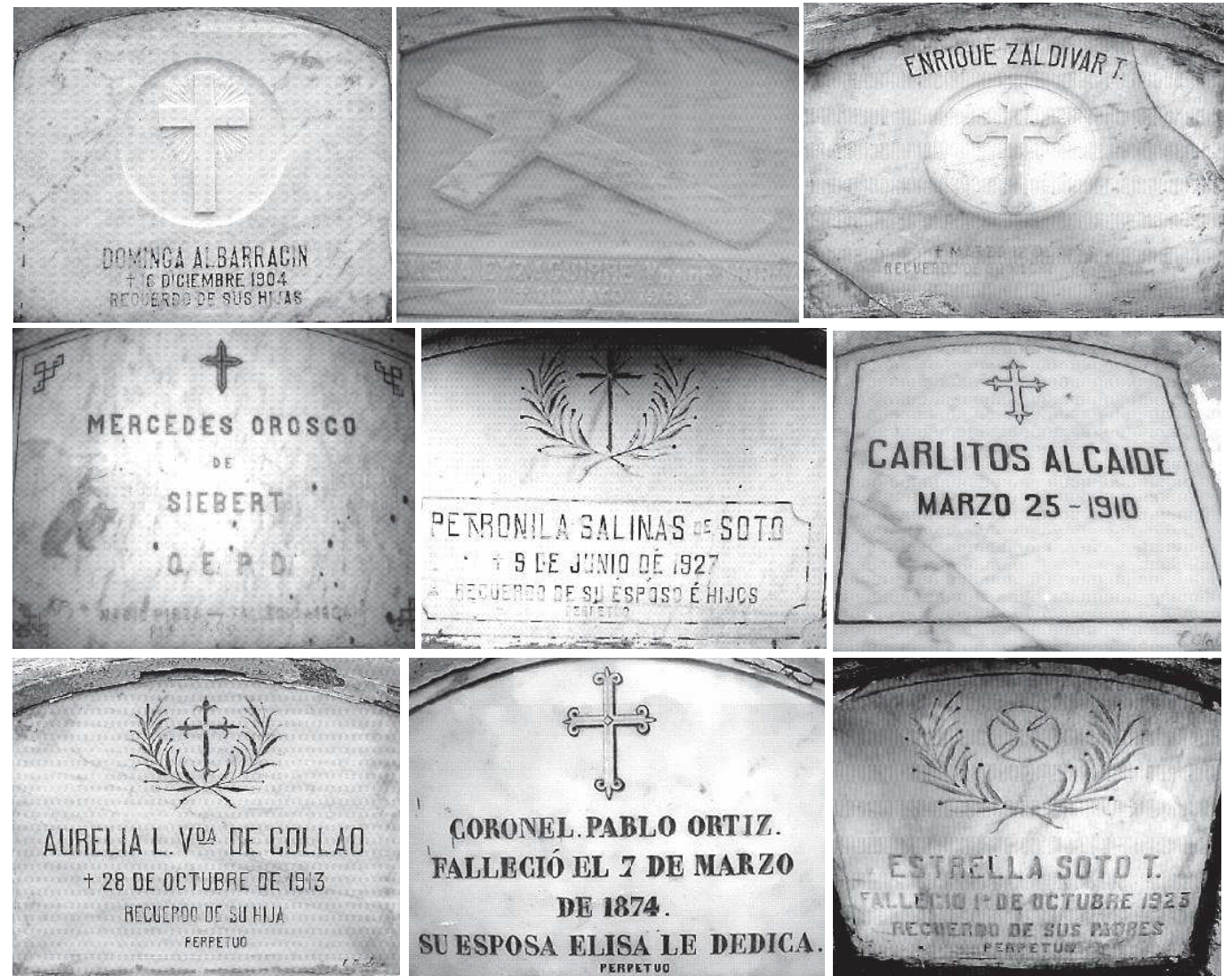

PETRON!LA SALINAS IS SQTA

S SE JUNIODE B27 S FETUEMTS DE SH ESPJSO É HIJOS

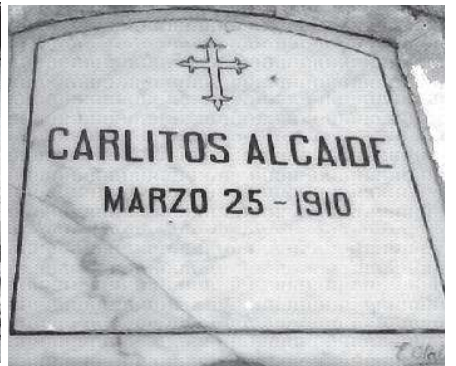

mat $=-1$ -

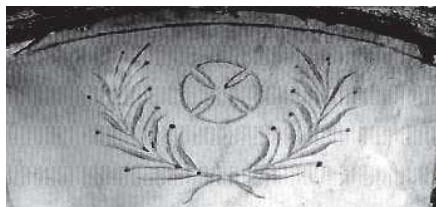

GORONEL. PABLO ORTIZ. FALLEGIÓ EL 7 DE MARZO DE 1874.

SU ESPOSA ELISA LE DEDICA.

ESTRELLA SOTOT. MLLERID I' UE OCTUBRE 1925 Recyengo oe sus nopes
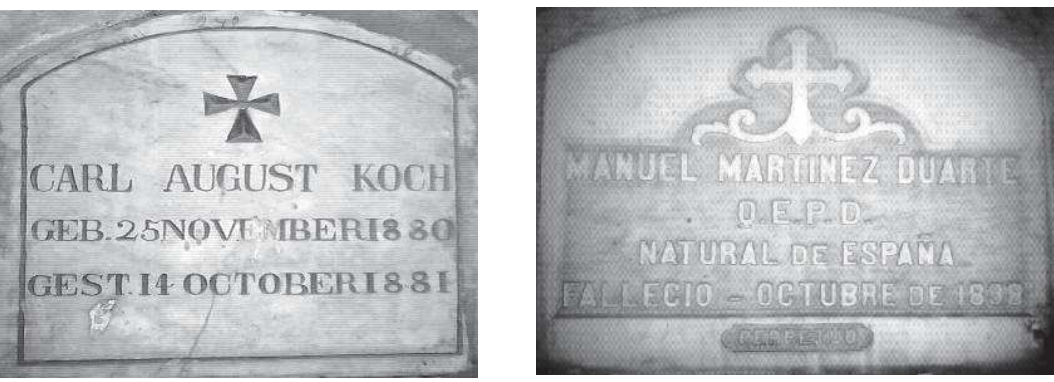

Figura 3. Lápidas con variaciones iconográficas de la cruz Fuente: Chaiña Flores Elard. 2014

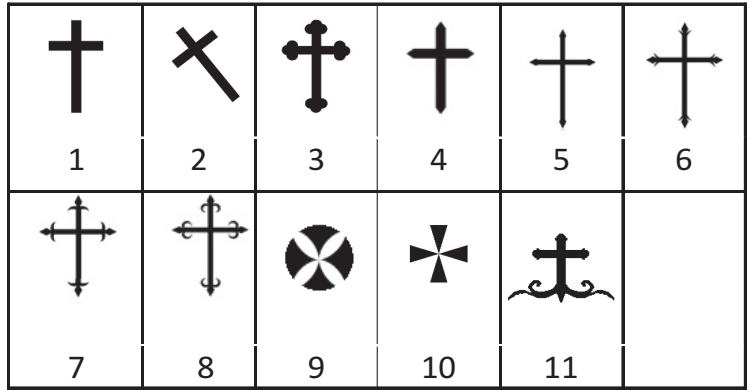

Figura 4. Variaciones iconográficas de la cruz

Fuente: Elaborado en base a información colectada 2014 - 2015 
La variante más utilizada del ícono de la cruz fue la 2, "Cruz vertical" con un 20\%, continuando con las varian"Cruz Diagonal" con un 55,5\%; seguido de la cruz 1, tes verticales.

Tabla 1. Cantidad y porcentaje de íconos cruz

\begin{tabular}{|l|l|l|}
\hline Tipo & Cantidad & \multicolumn{1}{c|}{$\%$} \\
\hline cruz 1 & 218 & $20,68 \%$ \\
\hline cruz 2 & 585 & $55,50 \%$ \\
\hline cruz 3 & 26 & $2,47 \%$ \\
\hline cruz 4 & 20 & $1,90 \%$ \\
\hline cruz 5 & 25 & $2,37 \%$ \\
\hline cruz 6 & 73 & $6,93 \%$ \\
\hline cruz 7 & 81 & $7,69 \%$ \\
\hline cruz 8 & 6 & $0,57 \%$ \\
\hline cruz 9 & 12 & $1,14 \%$ \\
\hline cruz 10 & 4 & $0,38 \%$ \\
\hline cruz 11 & 4 & $0,38 \%$ \\
\hline Total & $\mathbf{1 0 5 4}$ & $\mathbf{1 0 0} \%$ \\
\hline
\end{tabular}

Fuente: Elaborado en base a información colectada 2014 - 2015

Como ya advertía José Alcina (1998), cada lápida “[...] lleva su fecha inscrita con gran precisión, no habiendo un lapso mayor de un año entre la muerte del individuo y la construcción de la lápida conmemorativa" (p.137), lo que permite graficar cronológicamente (figura 5) la frecuencia de empleo del ícono cruz, permitiendo determinar las variaciones iconográficas y por décadas (tabla 2).

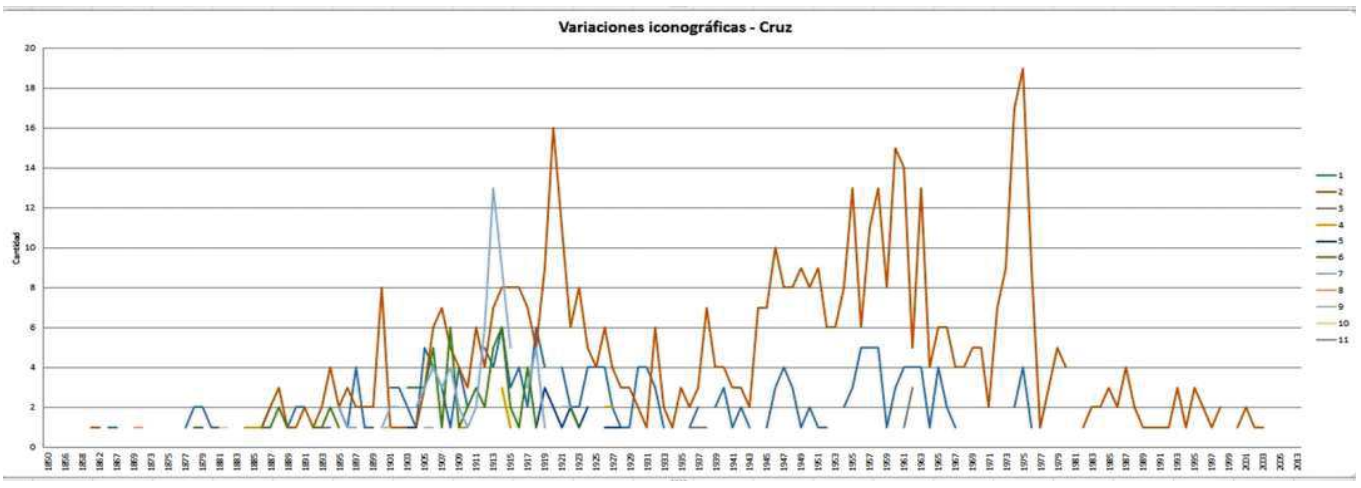

Figura 5. Cronología de las variaciones iconográficas

Fuente: Elaborado en base a información colectada 2014 - 2015 
Tabla 2. Variaciones iconográficas por décadas

\begin{tabular}{|c|c|c|c|c|c|c|c|c|c|c|c|c|c|c|c|c|}
\hline Década & 1850 & 1860 & \begin{tabular}{|l|l|}
1870 \\
\end{tabular} & 1880 & 1890 & 1900 & 1910 & 1920 & 1930 & 1940 & 1950 & 1960 & 1970 & 1980 & 1990 & 2000 \\
\hline 1 & & 十 & t & 十 & t & 十 & 十 & 十 & $t$ & 十 & $t$ & + & 十 & & & \\
\hline 2 & $x$ & & & $x$ & $x$ & $x$ & $x$ & $x$ & $x$ & $x$ & $x$ & $x$ & $x$ & $x$ & $x$ & $x$ \\
\hline 3 & & & & & † & & & & 千 & & & ff & & & & \\
\hline 4 & & & & $t$ & & & + & 十 & & & & & & & & \\
\hline 5 & & & & & & 十 & 十 & 十 & & & & & & & & \\
\hline 6 & & & 十 & 十 & + & + & + & 十 & & & & & & & & \\
\hline 7 & & & & & 中 & † & † & & & & & & & & & \\
\hline 8 & & & 中 & & & & & & & & & & & & & \\
\hline 9 & & & & & & $X$ & $x$ & & & & & & & & & \\
\hline 1 & & & & 市 & & & & & & & & & & & & \\
\hline 11 & & & & & & & te & te & & & t. & & & & $t_{2}$ & \\
\hline
\end{tabular}

Fuente: Elaborado en base a información colectada 2014 - 2015

\section{Características de las variaciones iconográficas de la cruz}

La cruz, símbolo de la crucifixión de Jesucristo en donde el tramo vertical más largo que el horizontal; para la presente investigación se catalogó como la cruz $\mathrm{N}^{\circ}$ 1, en donde la verticalidad de la cruz nos remite a "Jesucristo, el hijo de Dios, murió en la cruz para redimir los pecados del mundo y luego resucitó" (Dorling, 2008), o como diría Morales (1986) para "la salvación de las almas pecadoras [...] en toda su imponente expresión de crucificado".

La variación iconográfica más predominante es la cruz $\mathrm{N}^{\circ} 2$, "la cruz diagonal, guarda relación con el becho de ser cargada por Jesucristo al calvario" (Chaiña, 2014), una cruz marcadamente latina "el tramo vertical más amplio que el horizontal, es el simbolo de la cruz en que fue crucificado Jesucristo aunque los primeros cristianos la consideraban atroz $y$ en vez de ella usaban el pez, fue gradualmente aceptada como símbolo de cristo." Dorling (2008), "nos recuerda el triunfo de cristo y la salvación que dios nos trae a través del paso de la cruz, por eso ese signo es entendido "la cruz que salva"'. (Burgos, S/f, p. 6), representación que pone en manifiesto los anhelos de los devotos católicos.

La variación iconográfica $\mathrm{N}^{\circ} 3$ de la cruz es la cruz trebolada, que "se forma a partir de la cruz latina, pero sus extremos [...] terminan en brotes como la hoja de trébol, símbolo de la trinidad" (Dorling, 2008).
Las cruces $\mathrm{N}^{\circ} 4$ y No 5 son variaciones estilísticas directas de la cruz latina.

Las variaciones iconográficas $\mathrm{N}^{\circ} 6, \mathrm{~N}^{0} 7$ y $\mathrm{N}^{\circ} 8$ corresponden a variaciones interpretativas de la denominada cruz flor de liseada, porque en los extremos de sus brazos terminados en forma de flores de lis, dan origen a muchas denominaciones.

La variación iconográfica $\mathrm{N}^{\circ} 9$ y $\mathrm{N}^{\circ} 10$ de la cruz, corresponde a la denominada cruz patada o cruz paté, es aquella cruz cuyos brazos se estrechan al llegar al centro y se ensanchan en los extremos, asociada a los caballeros templarios, caballeros teutónicos, Prusia y al Imperio alemán.

La variación iconográfica $\mathrm{N}^{\circ} 11$, corresponde añadidura a la cruz en su parte inferior de extensiones de hojas/volutas, representación del monte calvario.

\section{DISCUSIÓN}

Los íconos producidos por el ser humano sirven para intercambiar conocimientos, sentimientos y experiencias, así como para organizar un sistema de vida social, como ideologías, religión, ritos, costumbres, leyes y tradiciones; es así, que en el contexto católico del Cementerio General de Tacna, existen lápidas con variaciones iconográficas de la cruz.

La profusión de variaciones iconográficas de la cruz durante 1880 hasta 1930, (figura 5, tabla 2) corresponde al periodo del inicio de la Guerra del Pacífico en 1879 hasta el final del cautiverio en 1929, en dicho periodo 
existen hasta 9 variaciones del ícono de la cruz (ver cruz vertical-diagonal: figura 6).

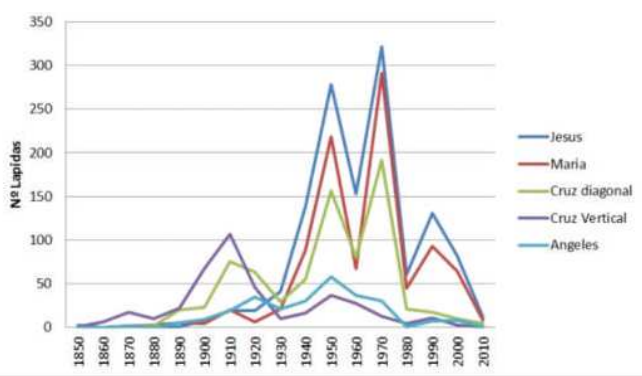

Figura 6. Íconos - Arte funerario del cementerio general de Tacna Fuente: Chaiña (2014, p. 26)

Estas variaciones iconográficas de la cruz debieron obedecer a la penosa realidad vivencial del poblador tacneño, que da cuenta de la idealización iconográfica de su fe y convicción, reflejo de su mentalidad que permite reflexionar "cómo percibieron los hombres del pasado los hechos que vivieron" (Truji1lo, 2003), estas variaciones iconográficas de la cruz representada en las lápidas reflejan el pensamiento como "representaciones colectivas que rigen los sistemas de identificación y de integración social, y que hacen visible la invisibilidad social" (Cano, 2011), la iconografía centrada solo en la cruz pone en manifiesto las penurias y anhelos de los tacneños de este periodo histórico frente el carácter efímero de lavida.

Evidenciando que las variaciones iconográficas de la cruz en el Cementerio General de Tacna, proliferaron en una coyuntura de guerra y ocupación.

\section{CONCLUSIONES}

Existen 11 variaciones estilísticas del ícono de la cruz del arte funerario de las lápidas del Cementerio General de Tacna que representa características de fe y tradición de un pueblo mayormente católico.

Las variaciones estilísticas del ícono de la cruz son precisas, corresponden a la cruz latina, cruz diagonal, cruz trebolada, cruces $\mathrm{N}^{\circ} 4 \mathrm{y} \mathrm{N}^{\circ} 5$, variaciones de la cruz latina; cruces $\mathrm{N}^{\circ} 6, \mathrm{~N}^{\circ} 7 \mathrm{y} \mathrm{N}^{\circ} 8$, variaciones interpretativas de la cruz flordeliseada; cruces patada $\mathrm{N}^{\circ} 9$ y $\mathrm{N}^{\circ} 10$ y la variación estilística $\mathrm{N}^{\circ} 11$ con extensiones de hojas-volutas.
Las mayores variaciones iconográficas de la cruz, se dieron durante la Guerra del Pacífico y el cautiverio de Tacna, como materialización de sus mentalidades.

\section{REFERENCIAS BIBLIOGRÁFICAS}

Alcina, J. (1998). Arte y antropología. Madrid: Alianza Editorial.

Atanasio, M. (1964). Carta escrita a la sociedad desde la ciudad del Cuzco, consequente á los Mercurios del folio 57, 236, 124, y 133 del tomo I. En Mercurio Peruano del día 26 de mayo de 1791. Tomo II. Edición facsimilar. Lima: Biblioteca Nacional del Perú.

Burgos, M. S/f. La cruzque salva. Tacna: S/edit.

Cano, A. (2011). De la historia de las mentalidades a la bistoria de los imaginarios sociales. Ciencias Sociales y Educación, Vol. 1, №1. Medellín: Universidad de Medellín.

Calvo, R. (2010). El histórico cementerio republicano (de la Almudena) y la cultura de la muerte Cusqueña. Cusco: Editorial Alpha Servicios Gráficos S.R.L.

Chaiña, E. (2014). Arte funerario e iconografía en Tacna Perú. La Vida y la Historia. Vol. II, $\mathrm{N}^{\circ} 01$. Tacna: UNJBG.

Dorling, K. (2008). Signos y símbolos. Editorial Dorling Kindersley. China.

García, J. (1981). La arquitectura en el Virreinato y la República. Historia del Perú - Procesos e Instituciones. Tercera edición. Lima: Juan Mejía Baca.

Mc Evoy, C. (2017). La Utopía republicana: Ideales y realidades en la formación de la cultura política peruana. Segunda edición. Lima: Fondo Editorial PUCP.

Millones, L. y Tomoeda, H. (2010). La cruz del Perú. Lima: Editorial del pedagógico San Marcos.

Morales, S. (1986). El santuario de Locumba. Tacna: Editorial J.A. Cuzzi.

Panofsky, E. (1987). El significado en las artes visuales. Cuarta reimpresión. Madrid: Alianza Forma

Rojas, R. (2017). La república imaginada: representaciones culturales y discursos políticos en la época de la independencia. Lima: IEP.

Rueda, N. (1982). Historia del departamento de Tacna. Tacna: S/E.

Trujillo, C. (2003). Hacia una historia de las mentalidades colectivas. Historia $\mathrm{N}^{0}$ 6. Arequipa: 
UNSA.

Wuffarden, L. (2006). Avatares del "bello ideal". Modernismo clasicista versus tradiciones barrocas en Lima, 1750-1825. En Visión y símbolos del virreinato criollo a la republica peruana. Lima: BCP.

Zora, F. (1969). Tacna Historia y Folklore. Segunda edición. Tacna: Santa María. 